OPEN ACCESS

Edited by:

Peter Klivenyi,

University of Szeged, Hungary

Reviewed by:

Seana Gall,

University of Tasmania, Australia

Miao Chen,

University of Shanghai for Science and

Technology, China

*Correspondence:

Xinyu Yu

yuxinyu7@hust.edu.cn orcid.org0000-0002-3689-980X

Liangtao Xia

xialiangtao@hust.edu.cn

Specialty section:

This article was submitted to

Stroke,

a section of the journal

Frontiers in Neurology

Received: 27 December 2020

Accepted: 08 March 2021

Published: 30 March 2021

Citation:

Yang S, Liu T, Wu Y, Xu N, Xia L and YuX (2021) The Role of Aspirin in the Management of Intracranial Aneurysms: A Systematic Review and Meta-Analyses.

Front. Neurol. 12:646613

doi: 10.3389/fneur.2021.646613

\section{The Role of Aspirin in the} Management of Intracranial Aneurysms: A Systematic Review and Meta-Analyses

\author{
Shuwen Yang ${ }^{1}$, Tianyu $L_{i u^{2}}$, Yuehui $W^{2}{ }^{2}$, Nina $X u^{2}$, Liangtao Xia ${ }^{3 *}$ and Xinyu $Y^{2 *}$ \\ ${ }^{1}$ Department of Neurosurgery, People's Hospital of Huangpi District, Jianghan University, Wuhan, China, ${ }^{2}$ Department of \\ Neurosurgery, Union Hospital, Tongji Medical College, Huazhong University of Science and Technology, Wuhan, China, \\ ${ }^{3}$ Division of Cardiothoracic and Vascular Surgery, Tongji Hospital, Tongji Medical College, Huazhong University of Science \\ and Technology, Wuhan, China
}

Objective: To evaluate the association between aspirin use and the risks of unruptured intracranial aneurysm (UIA) growth and aneurysmal subarachnoid hemorrhage (aSAH).

Methods: We searched PubMed and Scopus from inception to 1 September 2020. Studies evaluating the associations between aspirin prescription and the risk of UIA growth or the risk of aSAH were included. The study only included patients with intracranial aneurysms. We assessed the quality of included studies using the Newcastle-Ottawa scale. Random-effects meta-analysis was conducted to pool the estimates of effect size quantitatively. Sensitivity analyses using the leave-one-out strategy were performed to identify any potential source of heterogeneity.

Results: After a review of 2,226 citations, five cohort studies, two case-control studies, and one nested case-control study involving 8,898 participants were included. Pooled analyses showed that aspirin use, regardless of frequency and duration, was associated with a statistically significantly lower risk of UIA growth (OR $0.25,95 \% \mathrm{Cl} 0.11-0.54$; $\left.R^{2}=0.0 \%, p=0.604\right)$ and aSAH (OR, $\left.0.37,95 \% \mathrm{Cl}, 0.23-0.58 ; I^{2}=79.3 \%, p=0.001\right)$ in patients presented with intracranial aneurysms. The results did not significantly change in sensitivity analyses.

Conclusions: Summarizing available evidence in the literature, our findings indicate that aspirin use, regardless of frequency and duration, was associated with a statistically significantly lower risk of UIA growth and aSAH in patients with UIA. Well-designed and large-scale clinical trials are needed to help define the role of aspirin as a protective pharmaceutical for UIAs.

Keywords: aspirin, intracranial aneuryms, aneurysmal subarachnoid hemorrhage, prevention, meta-analysis

\section{INTRODUCTION}

According to global statistics, it is estimated that $3 \%$ of the adult population has an unruptured intracranial aneurysm (UIA) (1). With the development of non-invasive imaging techniques, an increasing number of UIAs are being detected (2). Despite the further expansion of endovascular techniques and surgical clipping in recent years, the incidence of aneurysmal subarachnoid 
hemorrhage $(\mathrm{aSAH})$ is relatively unchanged worldwide (3). Small aneurysms $(<7 \mathrm{~mm})$ are often left untreated because these patients cannot benefit from existing treatments, and the risk of aneurysm rupture does not outweigh the risk of morbidity and mortality from treatment complications for these aneurysms. Due to the non-negligible rate of aneurysm growth, regular follow-up with imaging surveillance to assess change in size and morphology is indicated (4-6). However, the continuous growth of an intracranial aneurysm results in subarachnoid hemorrhage (SAH), which has a mortality of $35 \%$, and leads to serval serious complications (7). Thus, there is an urgent need for a noninvasive pharmaceutical treatment that can mitigate the risk of UIA growth.

Recently, accumulative evidence has suggested that inflammation plays a critical role in the structural deterioration of the IA wall and its subsequent rupture (8). Several observational studies have linked a representative non-steroidal antiinflammatory drug-aspirin use with a slower rate of IA growth and lower risk of aSAH (4, 9-15). Aspirin has been widely prescribed as a standard secondary preventative agent in patients with risks of cardio- and cerebrovascular diseases. If aspirin is proved to have a beneficial effect on the risk of UIA growth with an acceptable safety profile, it could be a promising treatment option for this indication. As such, we conducted this systematic review and meta-analysis including patients with intracranial aneurysms to evaluate the association between aspirin use and risk of UIA growth and aSAH.

\section{METHODS}

\section{Search Strategy}

We conducted this systematic review and meta-analysis following the Preferred Reporting Items for Systematic Review and MetaAnalysis guidelines 2009 (16). This systematic review and metaanalysis was not registered in the PROSPERO database. We thoroughly searched PubMed and Scopus from inception to 1 September 2020. A combination of search terms related to aspirin use (i.e., acetylsalicylic acid,) and outcomes of interest (i.e., occurrence of aSAH, growth of UIA) were used in the search strategy. We also searched the references of the included articles for further information. The details of the search strategy for each of the databases are included in Supplementary Materials.

\section{Inclusion Criteria}

Two collaborators (SY. and LX) individually screened the studies from two databases for eligibility according to predefined selection criteria: (i) the research design was cohort, casecontrol, or cross-sectional study; (ii) the study population was patients with UIAs and aspirin was the exposure factor; (iii) the primary outcome contained the prevalence of UIA growth or aSAH; and (iv) the study reported the odds ratio (OR) and corresponding 95\% confidence intervals (CIs) (or OR and 95\%CI can be manually derived from the study). Reviews, animal studies, clinical trials, case reports, commentaries were excluded. Disagreements were solved in a discussion with a senior author (XY.).

\section{Data Extraction}

Two investigators attentively screened the titles and abstracts of articles and excluded irrelevant studies after duplicates were removed. After the first-round review, the same investigators retrieved full reports of those potentially eligible studies for details independently and then included studies that met the inclusion criteria. The disagreement was resolved in discussions with a third reviewer.

Data were extracted from retrieved articles by two reviewers independently. Details on the name of the first author, year of publication, region, study design, age and gender ratio of participants, exposures, primary outcomes, controls, OR with $95 \% \mathrm{Cis}$, and covariates adjusted rates, if available, were recorded.

\section{Quality Appraisal}

We appraised included studies using the Newcastle-Ottawa Scale 10 , which is a nine-point scoring system used to assess the quality of non-randomized studies included in a systematic review/metaanalysis. A high-quality study was defined as a study with at least seven points. All items were independently assessed by two investigators with disagreements resolved by group discussion.

\section{Statistical Analysis}

We preferred to pool adjusted ORs from the primary studies; otherwise, we used the unadjusted estimates. A random-effects model was used to pool the effect estimates and $I^{2}$ statistic was used to evaluate heterogeneity (0-100\%). We considered $I^{2}<50 \%$ as low heterogeneity, $I^{2}$ of $50-75 \%$ as moderate heterogeneity, and $I^{2}>75 \%$ as statistically high heterogeneity. We performed sensitivity analyses using a "leave-one-out" strategy to clarify the potential sources of the heterogeneity between included studies which may result from differences in the study population, intervention, or comparators. Also, we planned to assess for publication bias by the Egger test and funnel plots. All analyses were conducted in Stata version 11.

\section{RESULTS}

\section{Literature Search}

Figure 1 displays the flow chart of our study. We identified 2,226 citations from PubMed and Scopus. Eight studies met the inclusion criteria and provided data with 8,898 distinct participants: one prospective cohort study reported associations between aspirin use and UIA growth/rupture; four retrospective studies of either a prospectively maintained database, a patient cohort, or a consecutive series, indicated a negative relationship between aspirin use and UIA growth or aSAH; two case-control studies and 1 nested case-control study discussed the relationship between aspirin use and risk of aSAH. Table 1 illustrates the detailed characteristics of the included studies, whose quality was carefully assessed by the Newcastle-Ottawa Scale (see Table 2).

\section{Outcome Measure}

\section{Aspirin Use and the Risk of UIA Growth}

Three studies reported associations between aspirin use and UIA growth. Although Serrone et al. identified a relatively lower risk in aspirin users (OR 0.72, 95\% CI 0.29-1.81), 


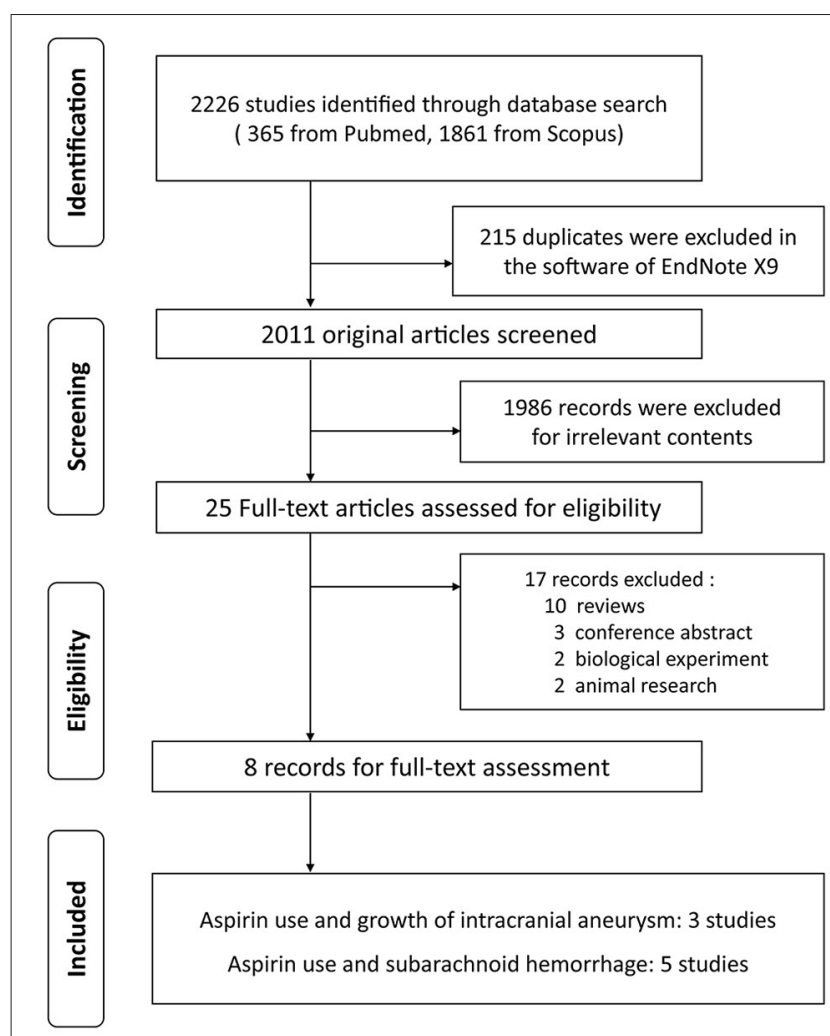

FIGURE 1 | Study screening flowchart.

their primary outcome was UIA growth or de novo aneurysm formation (14). Thus, we excluded it from the pooled analyses. Combining findings from the other two studies suggested that aspirin use, regardless of frequency and duration, was associated with a significantly lower risk of UIA growth (OR 0.25, 95\% CI 0.11-0.54) (Figure 2). No significant heterogeneity was observed $(p=0.604)$.

\section{Aspirin Use and the Risk of aSAH in Patients With UIA}

Five studies reported on the association between aspirin use and risk of aSAH in patients with UIA. A meta-analysis was conducted to pool estimates of aspirin use and the risk of aSAH in UIA patients, resulting in an OR of 0.37 (95\% CI, 0.230.58) (Figure 3). Significant heterogeneity was tested out in the included studies $(p=0.001)$. We then conducted a sensitivity analysis using a leave-one-out strategy. Figure 4 showed the corresponding pooled ORs when one study was excluded from the final analysis. The results remained stable when any specific study was excluded from the pooled analysis, indicating that aspirin use was associated with a lower risk of aSAH in patients with UIA despite the high heterogeneity in studies.

\section{DISCUSSION}

In the present systematic review and meta-analysis, we summarized all available epidemiological evidence, using data from 8,898 participants involving 581 cases in the aspirin users to help clarify the association between aspirin use and UIA growth or aSAH in UIA patients. Our results showed that aspirin use, regardless of frequency and duration, was associated with a statistically significant decreased risk of UIA growth (OR 0.25, 95\% CI $\left.0.11-0.54 ; I^{2}=0.0 \%, p=0.604\right)$ and a significantly lower risk of aSAH (OR, 0.37, 95\% CI, 0.23-0.58; $I^{2}=79.3 \%, p=$ 0.001 ) in patients with UIAs. The results of this study suggest that aspirin could play a role in reducing the risk of intracranial aneurysm expansion and the risk of aSAH, and aspirin could be a potential drug to treat intracranial aneurysms.

Two previous meta-analyses have discussed the effect of aspirin prescription on the risk of aSAH $(6,19)$. Both metaanalyses found no significant difference between aspirin users and non-aspirin users regarding the risk of aSAH (OR, 1.00; 95\% CI, 0.81-1.24, $p=0.99$, and OR, 0.981,95\% CI, 0.773-1.312, $p$ $=0.897)$. However, neither of the two meta-analyses focused on the risk of aSAH in the specific patient group with intracranial aneurysms, which may attenuate the possible protective effect of aspirin on IA rupture and aSAH in UIA patients. Moreover, better concomitant risk factor management in the UIA patients, particularly blood pressure control, might contribute to the lower risk of UIA progression. Besides, Phan et al. reported a significant association between short-term use of aspirin $(<3$ months) and risk of aSAH (OR, 1.61; 95\% CI, 1.20-2.18, $p$ $=0.002$ ) (6). Qian et al. also reported that short-term use of aspirin ( $<3$ months) was associated with an elevated risk of aSAH (OR, 1.697, 95\% CI, 1.175-2.452, $p=0.005)$ (19). They concluded that when prescribing aspirin for prophylactic use, particularly with known UIAs, its inherent bleeding risks should be taken into consideration, especially in the short term. Several population-based studies have explored the association between antiplatelet therapy and SAH, reaching conflicting results (20, 21). Recently, Weng et al. provided Class III evidence in a prospective, multicenter cohort that for patients harboring UIAs $<7 \mathrm{~mm}$ with ischemic cerebrovascular disease, aspirin does not increase the risk of aneurysm rupture (17). Together with our findings, we believe that the benefit of aspirin uses in this specific population outweighs the possibly increased risk of aSAH.

Both animal experiments and human clinical studies indicate that vascular remodeling and inflammatory cascades are crucial in the formation, progression, and rupture of IAs (22). Abnormal wall shear stress-activated the PGE2 (prostaglandin E2) -EP2 (prostaglandin E receptor 2) pathway in endothelial cells (ECs) at the early stage of cerebral aneurysm formation $(23,24)$. Subsequently, vascular smooth muscle cell apoptosis and migration, accompanied by inflammatory cell infiltration, resulted in degradation of the vascular wall, leading to the progression, and eventual rupture of IAs (22). Hasan et al. found in a small patient group that cyclooxygenase-2 (COX2) and microsomal prostaglandin E2 synthase-1 (mPGES-1) are expressed in human cerebral aneurysms and expression increases in ruptured aneurysms (25). Thus, drugs targeting molecules involved in the above process might have potential therapeutic effects. As a commonly used preventative agent in patients with risks of cardio- and cerebrovascular diseases, aspirin has been shown to have inhibitory effects on several 
TABLE 1 | Characteristics of included studies in the systematic review.

\begin{tabular}{|c|c|c|c|c|c|c|c|c|}
\hline $\begin{array}{l}\text { Study Authors and } \\
\text { Published Year } \\
\text { (location) }\end{array}$ & $\begin{array}{l}\text { Study } \\
\text { design }\end{array}$ & $\begin{array}{l}\text { Inclusion criteria for } \\
\text { participants }\end{array}$ & Definition of aspirin users & $\begin{array}{l}\text { Number of } \\
\text { Cases in the } \\
\text { exposure } \\
\text { group }\end{array}$ & $\begin{array}{l}\text { Follow-up } \\
\text { Duration, } \\
\text { mean }\end{array}$ & Definition of outcomes & $\begin{array}{l}\text { Adjusted estimate, }(95 \% \\
\text { Cl)/other outcomes }\end{array}$ & $\begin{array}{l}\text { Adjustment of } \\
\text { covariates }\end{array}$ \\
\hline Weng et al. (17) & $\begin{array}{l}\text { Prospective } \\
\text { cohort study }\end{array}$ & $\begin{array}{l}\text { Patients with UIAs }<7 \mathrm{~mm} \\
\text { and concurrent ischemic } \\
\text { cerebrovascular diseases } \\
\text { between Jan } 2016 \text { and Dec } \\
\text { 2019. }(n=272)\end{array}$ & $\begin{array}{l}\text { Aspirin users were defined } \\
\text { as those who reported } \\
\text { aspirin use at least } 3 \times \text { per } \\
\text { week, including standard- } \\
\text { and low-dose aspirin. } \\
\text { Non-aspirin users were } \\
\text { those who used no aspirin. }\end{array}$ & 113 & 19.6 months & $\begin{array}{l}\text { The primary outcome: } \\
\text { Aneurysm growth, which was } \\
\text { defined as [1] growth } \geq 1.0 \mathrm{~mm} \text { in } \\
\text { at least } 1 \text { direction by identical } \\
\text { imaging modalities, [2] growth } \\
\geq 0.5 \mathrm{~mm} \text { in } 2 \text { directions by } \\
\text { identical imaging modalities, and } \\
\text { [3] an indisputable change in } \\
\text { aneurysm shape. } \\
\text { The secondary outcome: } \\
\text { UIA rupture. The diagnosis of } \\
\text { aneurysm rupture was confirmed } \\
\text { by preoperative CT, MR imaging, } \\
\text { cerebrospinal fluid analysis, or a } \\
\text { neurosurgeon during operation. }\end{array}$ & $\begin{array}{l}\text { The primary outcome: } \\
\text { HR, } 0.29 \text { ( } 0.11-0.77) \text { The } \\
\text { cumulative annual growth } \\
\text { rates were as high as } 40.0 \\
\text { and } 53.3 \text { per } 100 \\
\text { person-years in the high-risk } \\
\text { patients ( }>1 \text { risk factor) with } \\
\text { and without } \\
\text { aspirin, respectively. The } \\
\text { secondary outcome: No } \\
\text { aneurysm rupture }\end{array}$ & $\begin{array}{l}\text { Age, female sex, } \\
\text { hyperlipidemia, } \\
\text { pretransient ischemic } \\
\text { attack, or ischemic } \\
\text { stroke }\end{array}$ \\
\hline $\begin{array}{l}\text { Zanaty et al. (9) } \\
\text { (Japan) }\end{array}$ & $\begin{array}{l}\text { A } \\
\text { retrospective } \\
\text { review of a } \\
\text { prospectively } \\
\text { maintained } \\
\text { database }\end{array}$ & $\begin{array}{l}\text { [1] Patients harbored } \\
\text { multiple saccular IAs; [2] At } \\
\text { least one primary aneurysm } \\
\text { was treated with coiling, } \\
\text { stent-assisted coiling, flow } \\
\text { diversion, or microsurgical } \\
\text { clipping;[3] The remaining } \\
\text { aneurysms were } \leq 5 \mathrm{~mm} \text { in } \\
\text { size and observed for } \\
\text { growth; and [4] At least } 5 \\
\text { years of follow-up from the } \\
\text { initial treatment was } \\
\text { available. }(n=146)\end{array}$ & $\begin{array}{l}\text { Aspirin users were defined } \\
\text { as those who reported } \\
\text { aspirin use } \geq 81 \mathrm{mg} \text { daily. } \\
\text { Non-aspirin users were } \\
\text { those who used no aspirin. }\end{array}$ & 69 & $\begin{array}{l}\text { More than } 5 \\
\text { years }\end{array}$ & $\begin{array}{l}\text { The primary outcome: the } \\
\text { interval growth of any remaining } \\
\text { untreated aneurysms that later } \\
\text { required treatment. Growth was } \\
\text { defined as an increase in the size } \\
\text { of the aneurysm } \geq 1 \mathrm{~mm} \text {. All } \\
\text { aneurysms that demonstrated } \\
\text { growth underwent treatment } \\
\text { regardless of size. }\end{array}$ & $\begin{array}{l}\text { The primary outcome: } \\
\text { OR, } 0.19(0.05-0.63)\end{array}$ & $\begin{array}{l}\text { Patient sex and age, } \\
\text { aneurysm size and } \\
\text { location, rupture status } \\
\text { of the designated } \\
\text { primary aneurysm at } \\
\text { the initial encounter, } \\
\text { hypertension, diabetes } \\
\text { mellitus, } \\
\text { hypercholesterolemia, } \\
\text { use of other } \\
\text { anticoagulant or } \\
\text { antiplatelet medication, } \\
\text { family history of IAs, } \\
\text { drug abuse, polycystic } \\
\text { kidney disease. }\end{array}$ \\
\hline $\begin{array}{l}\text { Serrone et al. (14) } \\
\text { (United States) }\end{array}$ & $\begin{array}{l}\text { A } \\
\text { retrospective } \\
\text { review of a } \\
\text { patient cohort }\end{array}$ & $\begin{array}{l}\text { Patients are seen in the } \\
\text { clinic with the diagnosis of } \\
\text { an untreated UIA and at } \\
\text { least } 1 \text { follow-up clinic visit } \\
\text { or consultation. }(n=192)\end{array}$ & $\begin{array}{l}\text { Aspirin users were defined } \\
\text { as those who reported } \\
\text { aspirin use. Non-aspirin } \\
\text { users were those who used } \\
\text { no aspirin. }\end{array}$ & 120 & 11.5 & $\begin{array}{l}\text { The primary outcome: } \\
\text { Aneurysm growth or de novo } \\
\text { aneurysm formation }\end{array}$ & $\begin{array}{l}\text { The primary outcome: } \\
\text { OR, } 0.72(0.29-1.81)\end{array}$ & NA \\
\hline $\begin{array}{l}\text { Gross et al. (11) } \\
\text { (United States) }\end{array}$ & $\begin{array}{l}\text { A } \\
\text { retrospective } \\
\text { review of a } \\
\text { consecutive } \\
\text { series }\end{array}$ & $\begin{array}{l}\text { Patients with at least one } \\
\text { cerebral aneurysm seen by } \\
\text { the neurosurgical service } \\
\text { during the study period. ( } n \\
=717 \text { ) }\end{array}$ & $\begin{array}{l}\text { Aspirin users were defined } \\
\text { as those who reported } \\
\text { aspirin use ( } 81 \text { or } 325 \mathrm{mg}) \text {. } \\
\text { Non-aspirin users were } \\
\text { those who used no aspirin. }\end{array}$ & 32 & 7 years & $\begin{array}{l}\text { The primary outcome: } \\
\text { aneurysmal subarachnoid } \\
\text { hemorrhage }\end{array}$ & $\begin{array}{l}\text { The primary outcome: } \\
\text { OR, } 0.58(0.38-0.90)\end{array}$ & NA \\
\hline
\end{tabular}

stent-assisted coiling, flow clipping;[3] The remaining aneurysms were $\leq 5 \mathrm{~mm}$ in observed for of follow-up from the initial treatment was Patients are seen in the 
Study Authors and Study

Published Year design

(location)

design

Inclusion criteria for

participants

\section{Can et al. (12)}

(United States)

Case-control Patients who were

diagnosed with an

intracranial aneurysm

between
$=4,619)$.

and 2016

Definition of aspirin users
Aspirin users were defined
as those who reported
aspirin use. Non-aspirin

no aspirin.
Nisson et al. (15) (United States)

Hasan et al. (10) (United States)
Hostettler et al. (13) Case-control (United Kingdom) study

Patients with aneurysmal SAH or unruptured

aneurysm without previous $\mathrm{SAH}$ enrolled in the Genetic and Observational Subarachnoid Hemorrhage study $(n=2,334)$.

Aspirin use was defined by patient self-reporting or

available documentation on regular intake at the time of either admission with aneurysmal SAH or of being diagnosed with an unruptured aneurysm

Retrospective Patients who underwent cohort study surgery for intracranial Aspirin users were defined as those who reported aneurysm between January aspirin use. Non-aspirin 2010 and April 2013 at a $\quad$ users were those who used tertiary academic medical no aspirin. center $(n=347)$.

Nested [1] Patients must have at Aspirin users were defined case-control least one UIA, which may or as those who reported study

may not be symptomatio. aspirin use based [2] Patients who have had a on questionnaires. ruptured aneurysm at Non-aspirin users were another location that was those who used no aspirin isolated, trapped, clipped,

or treated through

endovascular obliteration

must be able to care for

themselves after the

aneurysmal treatment

according to a follow-up

evaluation at 30 days of

post-treatment. $(n=271)$

\section{The primary outcome: \\ aneurysmal subarachnoid}

hemorrhage

\section{The primary outcome: aneurysmal subarachnoid hemorrhage}

The primary outcome:

UIA rupture. The adjudicated

hemorrhage events were defined

as a primary hemorrhage if

either: [1] a definite or highly

probable SAH of aneurysmal or

unknown etiology or [2] a definite

or highly probable intracranial

hemorrhage determined to be of

aneurysmal etiology.
Adjusted estimate, $195 \%$ Adjustment of

Cl)/other outcomes

covariates

The primary outcome: Age, sex, and race

OR, $0.60(0.45-0.80)$

and comorbid

conditions, including

hypertension, coronary artery disease,

myocardial infarction,

and atrial fibrillation,

antihypertensive

medication use, family history of aneurysms or $\mathrm{SAH}$, and current

tobacco and alcohol

use.

The primary outcome: Age, sex, ethnicity,

OR, $0.28(0.20-0.40) \quad$ smoking status, use of

antihypertensive

medication,

hypercholesterolemia aneurysm location aneurysm size.

The primary outcome: NA

OR, $0.18(0.09-0.39)$

The primary outcome: Age, sex, UIA OR, 0.27 (0.11-0.67) enrollment group, participating center location, multiple aneurysm,

hypertension, cardiac valvar disease, atrial fibrillation-flutter, other cardiac arrhythmias, congestive heart failure, myocardial infarction, family history of

intracranial aneurysm hemorrhage, smoking alcohol consumption, use of anticoagulants, history of aneurysms, interaction smoking and hypertension. 
TABLE 2 | Newcastle-Ottawa scale for assessing the quality of included studies.

\begin{tabular}{|c|c|c|c|c|c|}
\hline Study design & Author, year (Pubmed ID) & $\begin{array}{l}\text { Selection } \\
(\operatorname{Max}=4)\end{array}$ & $\begin{array}{l}\text { Comparability } \\
\text { (Max=2) }\end{array}$ & $\begin{array}{c}\text { Exposure } \\
(\mathrm{Max}=3)\end{array}$ & $\begin{array}{c}\text { Overall } \\
\text { quality score } \\
(\operatorname{Max}=9)\end{array}$ \\
\hline \multirow{3}{*}{$\begin{array}{l}\text { Case-control } \\
\text { study }\end{array}$} & Can et al. (12) (30135253) & 4 & 2 & 2 & 8 \\
\hline & Hostettler et al. (13) (28973585) & 4 & 2 & 2 & 8 \\
\hline & Hasan et al. (18) (21980208) & 4 & 2 & 2 & 8 \\
\hline Study design & Author, year (Pubmed ID) & $\begin{array}{l}\text { Selection } \\
(\operatorname{Max}=4)\end{array}$ & $\begin{array}{l}\text { Comparability } \\
(\operatorname{Max}=2)\end{array}$ & $\begin{array}{l}\text { Outcome } \\
(\mathrm{Max}=3)\end{array}$ & $\begin{array}{c}\text { Overall } \\
\text { quality score } \\
(\operatorname{Max}=9)\end{array}$ \\
\hline \multirow[t]{5}{*}{ Cohort study } & Weng et al. (32878566) & 4 & 2 & 3 & 9 \\
\hline & Nisson et al. (15) (31857268) & 4 & 1 & 3 & 8 \\
\hline & Zanaty et al. (9) (31662579) & 4 & 2 & 3 & 9 \\
\hline & Serrone et al. (14) (26967775) & 4 & 1 & 2 & 7 \\
\hline & Gross et al. (11) (23548847) & 4 & 1 & 3 & 8 \\
\hline
\end{tabular}

\section{Aspirin use and growth of intracranial aneurysm}

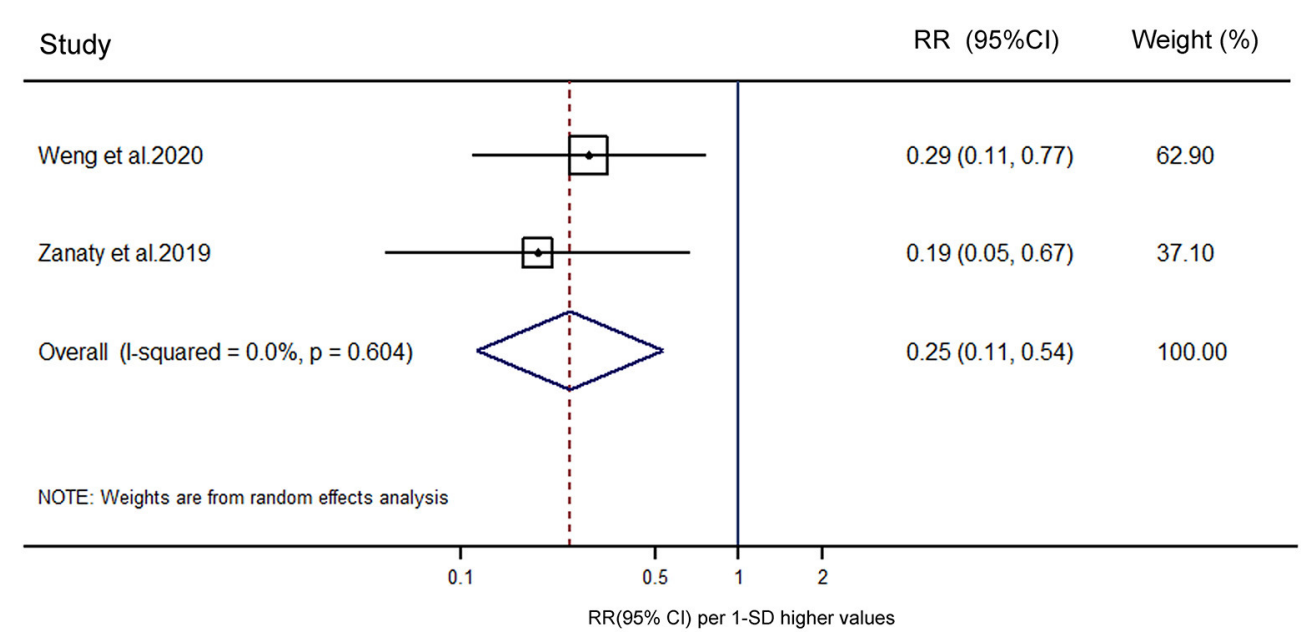

FIGURE 2 | Forest plot for an association between aspirin use and growth of intracranial aneurysm. OR, odds ratio; Cl, confidence interval.

inflammatory mediators such as COX-2 and mPGES-1, making it one of the promising drugs for decreasing UIA growth and rupture (10). Several groups have proved that acetylsalicylic acid (ASA) was associated with a slower IA growth rate and lower IA rupture or aSAH rate in mice IA-induction models, suggesting the protective effect of ASA against IA rupture (8). Moreover, Hasan et al. demonstrated a decreased expression of inflammatory cells and markers such as COX-2 in a small randomized sample of patients with unruptured aneurysms who underwent microsurgical clipping after 3 months of aspirin treatment (18). More researches should be conducted to further elucidate the underlying mechanisms of this issue.

The present study was constrained by several limitations. Firstly, the number of included studies was relatively low, especially for the meta-analysis on UIA growth. Secondly, all eligible data included in the meta-analysis were extracted from observational studies and most studies were retrospective. Last but not least, heterogeneity among studies suggests that the effect of aspirin on UIA growth and rupture should be further confirmed by clinical trials. Re-analyzing existing nonrandomized data using advanced statistical techniques (i.e., inverse probably of treatment weighting) could better explore this association as well.

\section{CONCLUSION}

Summarizing available evidence in the literature, our findings indicate that aspirin use, regardless of frequency and duration, 


\section{Aspirin use and risk of subarachnoid hemorrhage}

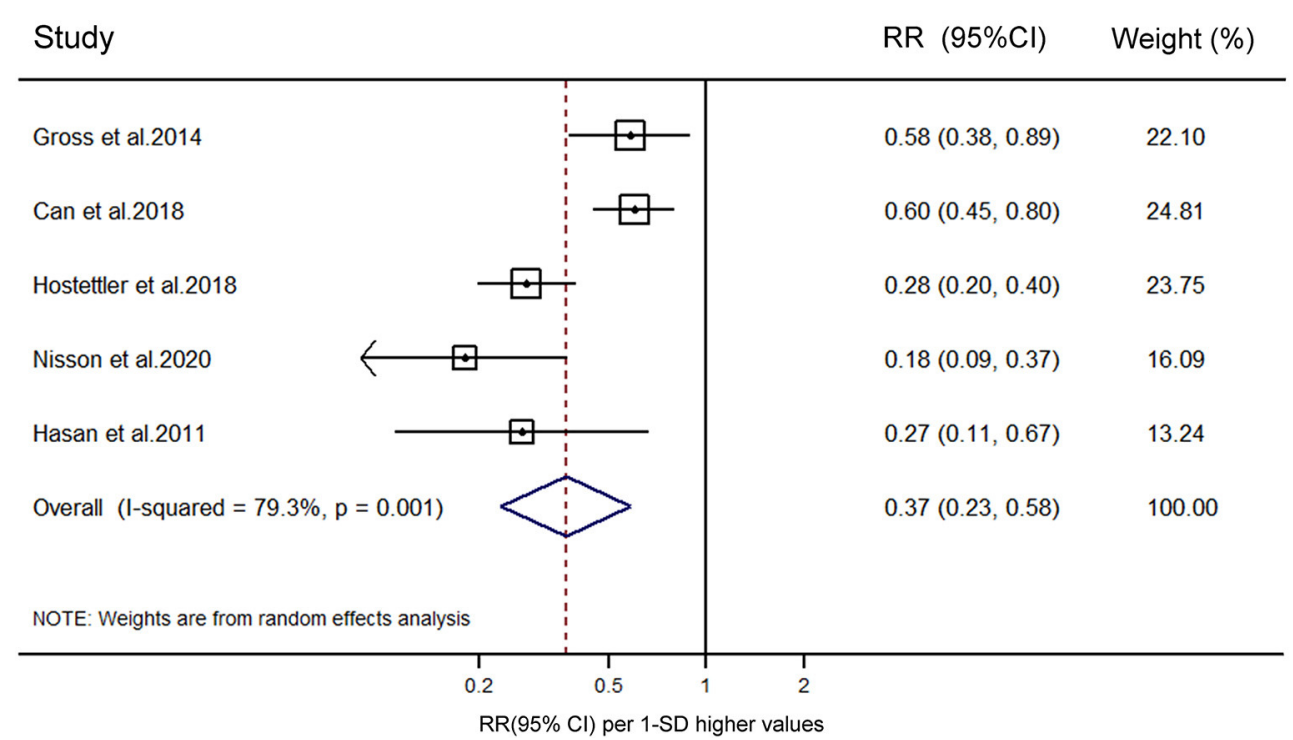

FIGURE 3 | Forest plot for an association between aspirin use and risk of subrachnoid hemorrhage. OR, odds ratio; Cl, confidence interval.

\section{Sensitivity analyses}

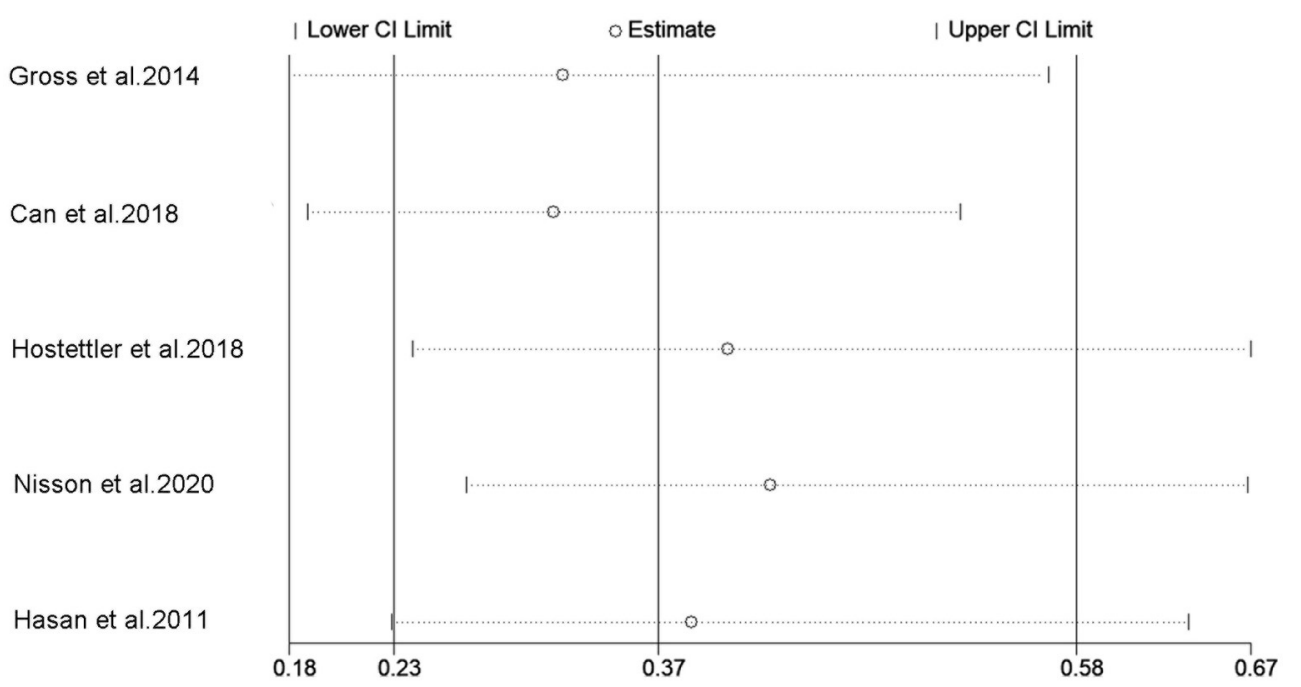

FIGURE 4 | Sensitivity analysis for an association between aspirin use and risk of subrachnoid hemorrhage. OR, odds ratio; Cl, confidence interval.

was associated with a statistically significant decreased risk of UIA growth and aSAH in UIA patients. Aspirin might be a potential drug for the treatment of intracranial aneurysms. Welldesigned, large-scale clinical trials are needed to help definitively define aspirin's role as a protective pharmaceutical for UIAs.

\section{AUTHOR CONTRIBUTIONS}

SY, LX, and XY contributed to the conception or design of the work and contributed to the acquisition, analysis, or interpretation of data for the work. SY and LX drafted 
the manuscript. TL, YW, and NX critically revised the manuscript. All gave final approval and agree to be accountable for all aspects of work ensuring integrity and accuracy.

\section{FUNDING}

This work was supported by the Hubei Natural Science Foundation (2019CFB465).

\section{REFERENCES}

1. Vlak MH, Algra A, Brandenburg R, Rinkel GJ. Prevalence of unruptured intracranial aneurysms, with emphasis on sex, age, comorbidity, country, and time period: a systematic review and meta-analysis. Lancet Neurol. (2011) 10:626-36. doi: 10.1016/S1474-4422(11)70109-0

2. Gabriel RA, Kim H, Sidney S, McCulloch CE, Singh V, Johnston SC, et al. Ten-year detection rate of brain arteriovenous malformations in a large, multiethnic, defined population. Stroke. (2010) 41:21-6. doi: 10.1161/STROKEAHA.109.566018

3. Jalbert JJ, Isaacs AJ, Kamel H, Sedrakyan A. Clipping and coiling of unruptured intracranial aneurysms among medicare beneficiaries, 2000 to 2010. Stroke. (2015) 46:2452-7. doi: 10.1161/STROKEAHA.115.009777

4. Weng JC, Wang J, Li H, Jiao YM, Fu WL, Huo R, et al. Aspirin and Growth of Small Unruptured Intracranial Aneurysm: Results of a Prospective Cohort Study. Stroke. (2020) 51:3045-54. doi: 10.1161/STROKEAHA.120.029967

5. Malhotra A, Wu X, Gandhi D, Sanelli P, Matouk CC. Management of small, unruptured intracranial aneurysms. World Neurosurg. (2020) 135:37980. doi: 10.1016/j.wneu.2019.12.139

6. Phan K, Moore JM, Griessenauer CJ, Ogilvy CS, Thomas AJ. Aspirin and risk of subarachnoid hemorrhage: systematic review and meta-analysis. Stroke. (2017) 48:1210-7. doi: 10.1161/STROKEAHA.116.015674

7. Neifert SN, Chapman EK, Martini ML, Shuman WH, Schupper AJ, Oermann EK, et al. Aneurysmal subarachnoid hemorrhage: the last decade. Transl Stroke Res. (2020). doi: 10.1007/s12975-020-00867-0. [Epub ahead of print].

8. Hudson JS, Marincovich AJ, Roa JA, Zanaty M, Samaniego EA, Hasan DM. Aspirin and intracranial aneurysms. Stroke. (2019) 50:2591-6. doi: 10.1161/STROKEAHA.119.026094

9. Zanaty M, Roa JA, Nakagawa D, Chalouhi N, Allan L, Kasab SA, et al. Aspirin associated with decreased rate of intracranial aneurysm growth. J Neurosurg. (2019) 133:1-8. doi: 10.3171/2019.6.JNS191273

10. Hasan DM, Mahaney KB, Brown RD, Jr. et al. Aspirin as a promising agent for decreasing incidence of cerebral aneurysm rupture. Stroke. (2011) 42:3156-62. doi: 10.1161/STROKEAHA.111.619411

11. Gross BA, Rosalind Lai PM, Frerichs KU, Du R. Aspirin and aneurysmal subarachnoid hemorrhage. World Neurosurg. (2014) 82:1127-30. doi: 10.1016/j.wneu.2013.03.072

12. Can A, Rudy RF, Castro VM, Yu S, Dligach D, Finan S, et al. Association between aspirin dose and subarachnoid hemorrhage from saccular aneurysms: a case-control study. Neurology. (2018) 91:e117581. doi: 10.1212/WNL.0000000000006200

13. Hostettler IC, Alg VS, Shahi N, Jichi F, Bonner S, Walsh D, et al. Characteristics of unruptured compared to ruptured intracranial aneurysms: a multicenter case-control study. Neurosurgery. (2018) 83:43-52. doi: 10.1093/neuros/nyx365

14. Serrone JC, Tackla RD, Gozal YM, Hanseman DJ, Gogela SL, Vuong SM, et al. Aneurysm growth and de novo aneurysms during aneurysm surveillance. $J$ Neurosurg. (2016) 125:1374-82. doi: 10.3171/2015.12.JNS151552

15. Nisson PL, Meybodi T, Secomb TW, Berger GK, Roe DJ, Lawton MT. Patients taking antithrombotic medications present less frequently with ruptured aneurysms. World Neurosurg. (2020) 136:e132-40. doi: 10.1016/j.wneu.2019.12.045

\section{ACKNOWLEDGMENTS}

The authors would like to thank all the authors of the original articles.

\section{SUPPLEMENTARY MATERIAL}

The Supplementary Material for this article can be found online at: https://www.frontiersin.org/articles/10.3389/fneur. 2021.646613/full\#supplementary-material

16. Liberati A, Altman DG, Tetzlaff J et al. The PRISMA statement for reporting systematic reviews and meta-analyses of studies that evaluate health care interventions: explanation and elaboration. J Clin Epidemiol. (2009) 62:e134. doi: 10.1016/j.jclinepi.2009.06.006

17. Weng J-C, Wang J, Du X et al. Safety of aspirin use in patients with stroke and small unruptured aneurysms. Neurology. (2020) 96:e1929. doi: 10.1212/WNL.0000000000010997

18. Hasan DM, Chalouhi N, Jabbour P, Dumont AS, Kung DK, Magnotta VA, et al. Evidence that acetylsalicylic acid attenuates inflammation in the walls of human cerebral aneurysms: preliminary results. J Am Heart Assoc. (2013) 2:e000019. doi: 10.1161/JAHA.112.000019

19. Qian C, He Y, Li Y, Chen C, Zhang B. Association between aspirin use and risk of aneurysmal subarachnoid hemorrhage: a meta-analysis. World Neurosurg. (2020) 138:299-308. doi: 10.1016/j.wneu.2020.01.120

20. García-Rodríguez LA, Gaist D, Morton J, Cookson C, GonzálezPérez A. Antithrombotic drugs and risk of hemorrhagic stroke in the general population. Neurology. (2013) 81:56674. doi: 10.1212/WNL.0b013e31829e6ffa

21. Pottegård A, García Rodríguez LA, Poulsen FR, Hallas J, Gaist D. Antithrombotic drugs and subarachnoid haemorrhage risk. A nationwide case-control study in Denmark. Thromb Haemost. (2015) 114:106475. doi: 10.1160/TH15-04-0316

22. Liu Z, Ajimu K, Yalikun N, Zheng Y, Xu F. Potential therapeutic strategies for intracranial aneurysms targeting aneurysm pathogenesis. Front Neurosci. (2019) 13:1238. doi: 10.3389/fnins.2019. 01238

23. Jamous MA, Nagahiro S, Kitazato KT, Tamura T, Aziz HA, Shono M, et al. Endothelial injury and inflammatory response induced by hemodynamic changes preceding intracranial aneurysm formation: experimental study in rats. J Neurosurg. (2007) 107:405-11. doi: 10.3171/JNS-07/08/0405

24. Aoki T, Nishimura M, Matsuoka T, Yamamoto K, Furuyashiki T, Kataoka $\mathrm{H}$, et al. PGE2-EP2 signalling in endothelium is activated by haemodynamic stress and induces cerebral aneurysm through an amplifying loop via NFкB. Br J Pharmacol. (2011) 163:1237-49. doi: 10.1111/j.1476-5381.2011. 01358.x

25. Hasan D, Hashimoto T, Kung D, Macdonald RL, Winn HR, Heistad D. Upregulation of cyclooxygenase-2 (COX-2) and microsomal prostaglandin E2 synthase-1 (mPGES-1) in wall of ruptured human cerebral aneurysms: preliminary results. Stroke. (2012) 43:1964-7. doi: 10.1161/STROKEAHA.112.655829

Conflict of Interest: The authors declare that the research was conducted in the absence of any commercial or financial relationships that could be construed as a potential conflict of interest.

Copyright (c) 2021 Yang, Liu, Wu, Xu, Xia and Yu. This is an open-access article distributed under the terms of the Creative Commons Attribution License (CC BY). The use, distribution or reproduction in other forums is permitted, provided the original author(s) and the copyright owner(s) are credited and that the original publication in this journal is cited, in accordance with accepted academic practice. No use, distribution or reproduction is permitted which does not comply with these terms. 